\title{
Clinical and genomic findings in brain heterotopia: Report of a pediatric patient cohort from Romania
}

\author{
MAGDALENA BUDISTEANU ${ }^{1-3^{*}}$, SORINA MIHAELA PAPUC ${ }^{1 *}$, ALINA ERBESCU $^{1}$, CATRINEL ILIESCU $^{2,4}$, \\ MARIA DOBRE $^{1}$, DIANA BARCA ${ }^{2,4}$, OANA TARTA-ARSENE ${ }^{2,4}$, CRISTINA MOTOESCU ${ }^{2,4}$, ALICE DICA ${ }^{2}$, \\ CARMEN SANDU ${ }^{2,4}$, CRISTINA ANGHELESCU ${ }^{2}$, DANA CRAIU ${ }^{2,4}$ and AURORA ARGHIR ${ }^{1}$ \\ ${ }^{1}$ Medical Genetics Laboratory, Victor Babes National Institute of Pathology, 050096 Bucharest; \\ ${ }^{2}$ Department of Pediatric Neurology, Expertise Centre for Rare Diseases in Pediatric Neurology, Member of The EpiCARE \\ European Reference Network, 'Prof. Dr. Alex. Obregia' Clinical Hospital, 041914 Bucharest; \\ ${ }^{3}$ Department of Medical Genetics, Titu Maiorescu University, 040051 Bucharest; \\ ${ }^{4}$ Pediatric Neurology Discipline, Clinical Neurosciences Department, 'Carol Davila' University \\ of Medicine and Pharmacy, 050455 Bucharest, Romania
}

Received May 10, 2021; Accepted June 9, 2021

DOI: $10.3892 / \mathrm{etm} .2021 .11024$

\begin{abstract}
Brain heterotopia is a group of rare malformations with a heterogeneous phenotype, ranging from asymptomatic to a severe clinical picture (drug-resistant epilepsy, severe developmental delay). The etiology is multifactorial, including both genetic and environmental factors. In the present study, a cohort of 15 pediatric patients with brain heterotopia were investigated by clinical examination, electroencephalographic studies, brain imaging, and genomic tests. Most of the patients had epileptic seizures, often difficult to control with one antiepileptic drug; another frequent characteristic in the cohort was developmental delay or intellectual disability, in some cases associated with behavioral problems. The genomic studies revealed an interstitial 22q11.2 microduplication, an anomaly not reported previously in heterotopia patients. Comparing the cohort of the present study with that of a previous series of heterotopia patients, both adult and pediatric, similar aspects, such as the high frequency of drug-resistant epilepsy were observed as well as some differences, such as no systemic malformations and no cases with fatal evolution. The current findings add new data to existing knowledge on
\end{abstract}

Correspondence to: Dr Catrinel Iliescu, Department of Pediatric Neurology, Expertise Centre for Rare Diseases in Pediatric Neurology, Member of The EpiCARE European Reference Network, 'Prof. Dr. Alex. Obregia' Clinical Hospital, 10 Berceni Street, 041914 Bucharest, Romania

E-mail: catrinel.iliescu@gmail.com

*Contributed equally

Key words: cortical malformations, grey matter heterotopia, epilepsy, clinical variability, genetic heterogeneity, genomic imbalances a rare heterogeneous disorder. The detailed clinical description, including the epilepsy phenotypes, and genomic profiles bring new insights into a group of disorders, yet to be fully understood.

\section{Introduction}

Brain heterotopias are a rare group of congenital disorders, with an extremely variable clinical picture, ranging from asymptomatic (incidental findings) to severe, including drug-resistant epilepsy, global developmental delay, and behavior problems. Grey matter heterotopia (GMH) are cortical malformations generated by abnormal neuronal migration (1). However, disruption of other developmental processes such as neuronal progenitor proliferation and differentiation, seems to play a role in the pathogenesis (2). These disorders are characterized by a high heterogeneity of genetic anomalies and brain anatomical defects. Heterotopia can be isolated or co-exist with other brain malformation, including lissencephaly, agyria, microgyria, pachygyria, polymicrogyria, agenesis of the corpus callosum, porencephaly, schizencephaly, and agenesis of the cranial nerves (3-5). The routine clinical use of magnetic resonance imaging (MRI) of the brain has significantly increased the sensitivity of detection and the accuracy of GMH morphological description $(1,6)$. At the same time, recent technological advances in genetics and genomics have improved the capacity to unveil the complex genetic architecture of GMH and allowed identification of numerous pathogenic variants, mostly sequence changes, associated with a neuroanatomical or neurobehavioral phenotype. A wide range of genetic defects have been reported in GMH, from single nucleotide variants to copy number variations (CNVs) and chromosomal rearrangements (translocations, large deletions, and ring chromosomes) (2,7-11). However, the pathogenesis of GMH is multifactorial, the genetic factors interacting with environmental factors in different stages of neurodevelopment $(3,5)$. 
Several forms of heterotopia have been described: band heterotopia (or double cortex), subcortical heterotopia, and periventricular (subependymal) heterotopia $(1,12)$.

Thus, subcortical band heterotopia (SBH) caused by the mutation of the doublecortin $(D C X)$ gene on $\mathrm{X}$ chromosome, is present mostly in female patients and predominantly affects anterior brain regions. Females with this anomaly usually have developmental delay and epilepsy, but the severity of the symptoms can vary from mild to severe depending on the thickness of the heterotopia (13). Epileptic seizures can be generalized or focal or both, $65 \%$ of these patients having a drug-resistant form of epilepsy (14). The majority of male patients with $D C X$ mutations present classical lissencephaly with more severe abnormalities of the anterior brain (15). By contrast, males with mosaic $D C X$ mutations develop $\mathrm{SBH}$. For a small number of cases autosomal-dominant mutations in the platelet activating factor acetylhydrolase $1 \mathrm{~b}$ regulatory subunit 1 (PAFAH1Bl) gene have been associated with $\mathrm{SBH}$, the subcortical bands being localized predominantly in the parietal and occipital lobes (16). An autosomal recessive form of band heterotopia was described in patients with EMAP-like 1 (EML1) gene mutations (17). Patients with band heterotopia present, typically, with focal or generalized epileptic seizures, which evolve towards a severe, drug-resistant epilepsy, with different types of seizures (focal, generalized tonic clonic or tonic or atonic seizures) (18).

Periventricular nodular heterotopia $(\mathrm{PVNH})$ is the most common type of heterotopia, with an X-linked or autosomal inheritance. The most common clinical feature is epilepsy (up to 80\%) (13); epileptic seizures may be focal (aware or impaired awareness), generalized, or focal to bilateral tonic-clonic. Intellectual disability is a rare feature in unilateral localization $(<20 \%)$ but is very common in bilateral heterotopia (up to 60\%) (13). The X-linked PVNH is caused by mutations in Filamin A (FLNA), being reported in around $25 \%$ of sporadic cases and almost all familial forms $(2,19,20)$. Males with FLNA mutations usually die preor perinatally; the few reported surviving males have mosaic mutations or mutations which are less detrimental for FLNA functions. Some authors reported a common association between PVNH and congenital heart malformations, such as bicuspid aortic valve and patent ductus arteriosus in cases with mutations of the FLNA gene (21). Chiari II malformations/myelomeningocele were also found in association with nodular heterotopia (21).

Autosomal recessive forms of PVNH have been associated with mutations in ADP-ribosylation factor guanine exchange factor 2 (ARFGEF2), FAT atypical cadherin 4 (FAT4) and Dachsous cadherin-related 1 (DCHS1) (2,22). Heterozygous single nucleotide variants in ADP-ribosylation factor 1 (ARF1), ER membrane-associated RNA degradation (ERMARD), NEDD4-like E3 ubiquitin protein ligase $(N E D D 4 L)$ and microtubule-associated protein $1 \mathrm{~B}$ $(M A P 1 B)$ have been reported in autosomal-dominant PVNH $(8,23,24)$.

Another genetic cause of grey matter heterotopia is represented by the genomic rearrangements, i.e., losses or gains of genetic material affecting genes involved in pathways regulating neuronal migration. CNVs disrupting the FLNA gene were reported in PVNH, the genomic rearrangements being mediated by FLNA locus architecture $(20,25,26)$. Several well-characterized chromosomal syndromes associating heterotopia as part of the clinical picture were also reported: $5 p$ deletion (Cri-du-chat) syndrome, 22q11.2 deletion syndrome, $1 \mathrm{p} 36$ deletion syndrome, $6 \mathrm{q}$ deletion syndrome or $7 \mathrm{q} 11.23$ deletion syndrome (26-28). Accurate genotype-phenotype correlations in these syndromes are difficult due to the large size of genomic imbalances and high gene content. Moreover, these genomic defects are not specifically and recurrently associated with neuronal migration disorders.

Genetic heterogeneity should be taken into consideration in the establishment of algorithm of genetic investigation; another essential element is represented by clinical description (including family history) corroborated with imagistic data and other paraclinical data.

The aim of the present study was clinical and genomic investigations in a rare disorder cohort of heterotopia pediatric patients from Romania.

\section{Patients and methods}

Patients. In total, 15 patients (6 females and 9 males, with age at last follow-up ranging from 2 months to 24 years) with GMH were included in this study. The patients were evaluated at a tertiary health care center, Department of Pediatric Neurology, 'Prof Dr. Alex. Obregia' Clinical Hospital of Psychiatry. The diagnosis of heterotopia was based on brain MRI imaging $1.5 \mathrm{~T}$ according to the standard protocol which included T1, T2, FLAIR, and diffusion sequences. In one case, with initial MRI interpretation of cortical dysplasia, heterotopia was confirmed after the pathology examination of the malformed tissue, removed during epilepsy surgery. Six patients were available to date for peripheral blood sampling.

Clinical methods. For all the patients, general clinical examination was performed, which included anthropometric data collection (weight, height, frontal occipital circumference), skin and/or connective tissue anomaly assessment, dysmorphological examination, neurological and psychiatric examination, psychological tests [for IQ scoring, Portage, Raven, and WISC scales; autistic feature detection, ADOS, and ADI-R; attention deficit and hyperactivity disorder (ADHD) and other behavior problems] as well as routine clinical evaluation of other organs and systems. The patients were followed up for various intervals, ranging between 1 and 23 years, except for a 2-month-old child recently admitted to The Department of Pediatric Neurology.

Genetic methods. Genomic DNA (gDNA) was isolated with PureLink $^{\mathrm{TM}}$ Genomic DNA Mini kit (Thermo Fisher Scientific, Inc.) from the available peripheral blood samples according to the manufacturer's protocol. The quality of gDNA samples was assessed by spectrophotometry using Nanodrop 2000 (Thermo Fisher Scientific, Inc.). Array-based comparative genomic hybridization (array-CGH) was performed on gDNA using CytoSure Constitutional kit v3 4x180k (Oxford Gene Technology) and SurePrint G3 Human CGH Microarray kit, 4x180K (Agilent Technologies) according to the manufacturer's recommendations. 
Table I. Demographic and clinical characteristics of the patients with heterotopia.

\begin{tabular}{|c|c|c|c|c|c|c|c|c|}
\hline Patient & Sex & $\begin{array}{l}\text { Age at first } \\
\text { presentation }\end{array}$ & $\begin{array}{l}\text { Age at last } \\
\text { follow-up }\end{array}$ & $\begin{array}{l}\mathrm{DD} / \mathrm{ID} \\
\text { (degree of } \\
\text { severity) }\end{array}$ & $\begin{array}{l}\text { Behavioral } \\
\text { problems }\end{array}$ & $\begin{array}{l}\text { Epileptic } \\
\text { seizures }\end{array}$ & $\begin{array}{l}\text { Dysmorphic } \\
\text { features }\end{array}$ & Type of heterotopia \\
\hline \multirow[t]{2}{*}{1} & Male & 2 years & 3 years & $+($ Mild $)$ & $+($ Autism $)$ & - & + & Left frontal nodular \\
\hline & Male & 5 years & 6 years & - & - & + & - & Left nodular insular \\
\hline 3 & Male & 16 months & 16 years & + (Mild) & $+(\mathrm{ADHD})$ & + & - & Left occipital nodular \\
\hline 4 & Female & 6 months & 2 years & - & - & + & - & Left frontal nodular \\
\hline 5 & Male & 4 years & 16 years & + (Mild) & $+(\mathrm{ADHD})$ & + & - & $\begin{array}{l}\text { Right nodular } \\
\text { periventricular }\end{array}$ \\
\hline 6 & Female & 1 months & 4 years & - & - & + & - & $\begin{array}{l}\text { Left nodular } \\
\text { periventricular }\end{array}$ \\
\hline 7 & Female & 7 months & 17 years & $+($ Severe $)$ & - & + & + & $\begin{array}{l}\text { Left nodular } \\
\text { periventricular }\end{array}$ \\
\hline 8 & Female & 4 months & 24 years & $+($ Severe $)$ & $+($ Autism $)$ & + & - & $\begin{array}{l}\text { Bilateral periventricular } \\
\text { nodular }\end{array}$ \\
\hline 9 & Male & 16 months & 3 years & + (Mild) & - & - & + & $\begin{array}{l}\text { Left nodular } \\
\text { periventricular }\end{array}$ \\
\hline 10 & Male & 10 years & 14 years & - & - & + & - & $\begin{array}{l}\text { Left nodular and linear } \\
\text { frontal }\end{array}$ \\
\hline 11 & Male & 11 years & 11 years & - & - & + & - & $\begin{array}{l}\text { Focal left nodular } \\
\text { periventricular }\end{array}$ \\
\hline 12 & Female & 14 years & 16 years & - & - & + & - & $\begin{array}{l}\text { Bilateral periventricular } \\
\text { nodular predominantly } \\
\text { on the right }\end{array}$ \\
\hline 13 & Female & 2 months & 5 months & $+($ Mild $)$ & - & + & + & $\begin{array}{l}\text { Bilateral nodular } \\
\text { periventricular }\end{array}$ \\
\hline 14 & Male & 15 years & 17 years & - & $+(\mathrm{ADHD})$ & + & - & Right frontal nodular \\
\hline 15 & Male & 2 months & 2 months & + (Mild) & - & + & + & $\begin{array}{l}\text { Band heterotopia; } \\
\text { lissencephaly and corpus } \\
\text { callosum agenesis }\end{array}$ \\
\hline
\end{tabular}

ADHD, attention deficit and hyperkinesia disorder; DD, developmental delay; ID, intellectual disability.

Detection of CNVs was performed with Cytosure Interpret Software and Agilent Cytogenomics v 5.0.2.5. CNVs were classified into five categories (benign, likely benign, variant of uncertain significance, likely pathogenic, and pathogenic) according to the American College of Medical Genetics Guidelines (29). Database interrogation was used for assessing the genomic context and gene content of CNVs (30), the frequency of CNVs in the general population (The Database of Genomic Variants, DGV, http://dgv.tcag.ca/dgv/app/home) and in various patients from the DECIPHER database (31) using UCSC Genome Browser (https://www.genome.ucsc. edu/).

Written informed consent for participation in the study and for data publication was obtained from all the patients. In addition, parents or legal guardians of the patients signed the written informed consent.

The project was approved by The Ethics Committee of our institutions (Prof. Dr. Alex. Obregia Clinical Hospital of Psychiatry, Bucharest and Victor Babes National Institute of Pathology, Bucharest).

\section{Results}

Patients and epilepsy. A total of 15 patients with heterotopia were included in the present study: 6 females and 9 males, with age at last follow-up ranging from 2 months to 24 years. The clinical characteristics of the patients are summarized in Tables I and II. Most patients (13 of 15) were referred for epileptic seizures, and only two children presented with developmental delay. Of note, 8 patients had intellectual disability or developmental delay, mild in 6 cases and severe in 2 cases. Speech was delayed in 4 patients, and 5 subjects presented behavioral problems, including autism (2 patients), and hyperkinesia with attention deficit ( 3 cases). Of the 15 patients, 5 patients had dysmorphic facial features, which included hypertelorism, synophrys, high forehead, malformed ears, short nasal philtrum, micrognathia, and thin lips. Association of heterotopia with other brain malformation was found in 2 of 15 patients.

Regarding the epileptic seizures, most patients had focal seizures with or without bilateral tonic-clonic seizures, with focal discharges on EEG. Most of these patients (9 patients) 
Table II. Characteristics of the epileptic seizures.

\begin{tabular}{|c|c|c|c|c|c|}
\hline Patient & $\begin{array}{l}\text { Age of } \\
\text { onset }\end{array}$ & Type of seizures & EEG & Antiepileptic drugs & $\begin{array}{l}\text { Response } \\
\text { to therapy }\end{array}$ \\
\hline 2 & 5 years & Bilateral tonic-clonic & $\begin{array}{l}\text { Left temporal-occipital } \\
\text { spike-waves discharges }\end{array}$ & Valproate, carbamazepine & $+^{\mathrm{a}}$ \\
\hline 3 & 1.6 years & Focal impaired awareness & $\begin{array}{l}\text { Left frontal-central } \\
\text { spike-wave discharges }\end{array}$ & $\begin{array}{l}\text { Valproate, lamotrigine, } \\
\text { carbamazepine, clonazepam }\end{array}$ & - \\
\hline 4 & 6 months & Focal impaired awareness & $\begin{array}{l}\text { Left frontal spike-wave } \\
\text { discharges }\end{array}$ & Levetiracetam & + \\
\hline 5 & 4 years & $\begin{array}{l}\text { Bilateral tonic-clonic; } \\
\text { focal impaired awareness }\end{array}$ & $\begin{array}{l}\text { Right frontal-central } \\
\text { spikes-wave discharges }\end{array}$ & $\begin{array}{l}\text { Valproate, topiramate, } \\
\text { clonazepam }\end{array}$ & + \\
\hline 6 & 2 years & Bilateral tonic-clonic & $\begin{array}{l}\text { Focal spikes-wave } \\
\text { discharges }\end{array}$ & Levetiracetam & + \\
\hline 7 & 6 months & Focal impaired awareness & Left spike-wave discharges & $\begin{array}{l}\text { Levetiracetam, lamotrigine, } \\
\text { topiramate, valproate, } \\
\text { clonazepam }\end{array}$ & - \\
\hline 8 & 4 months & $\begin{array}{l}\text { Epileptic spasms, } \\
\text { generalized tonic seizures } \\
\text { and focal seizures }\end{array}$ & $\begin{array}{l}\text { Continuous spike-wave } \\
\text { discharges }\end{array}$ & $\begin{array}{l}\text { Valproate, topiramate, } \\
\text { clobazam }\end{array}$ & - \\
\hline 10 & 10 years & $\begin{array}{l}\text { Focal to bilateral } \\
\text { tonic-clonic }\end{array}$ & Focal left spikes & Levetiracetam & + \\
\hline 11 & 11 years & Focal seizures & $\begin{array}{l}\text { Bilateral spike-wave and } \\
\text { poly-spikes }\end{array}$ & $\begin{array}{l}\text { Valproic acid, levetiracetam, } \\
\text { clonazepam, carbamazepine }\end{array}$ & - \\
\hline 12 & 14 years & Focal seizures & Right temporal ictal activity & Oxcarbazepine, lamotrigine & - \\
\hline 13 & 2 months & Generalized and focal & $\begin{array}{l}\text { No epileptiform } \\
\text { abnormalities }\end{array}$ & Phenobarbital & + \\
\hline 14 & 15 years & Focal & $\begin{array}{l}\text { Spikes and spike-wave in } \\
\text { fronto-temporal right } \\
\text { derivates }\end{array}$ & Carbamazepine, clobazam & + \\
\hline 14 & $\begin{array}{l}\text { First day } \\
\text { of life }\end{array}$ & $\begin{array}{l}\text { Tonic generalized and } \\
\text { focal seizures }\end{array}$ & Hypsarrhythmia & $\begin{array}{l}\text { Fenobarbital, } \\
\text { levetiracetam }\end{array}$ & $+^{\mathrm{b}}$ \\
\hline
\end{tabular}

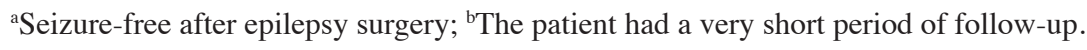

received more than one antiepileptic drug, in 7 cases with a good control of seizures; in 1 case the seizure control was obtained after surgical removal of the heterotopia.

None of our patients had a positive family history both for epilepsy and brain malformation.

Follow up. During the follow-up, the characteristic of seizures changed in 1 patient (patient 8, Table II) from epileptic spasms at onset (4 months of age) to tonic seizures and focal impaired awareness seizures (after the age of 2 years). A cognitive decline was noted in a patient with drug-resistant epilepsy (patient 3, Table II), with a decrease in IQ from 86 at the age of 9 years to 65 at 16 years. Patient 5 (Table I) had severe behavioral problems [attention deficit and hyperkinesia disorder (ADHD)], which preceded the first epileptic seizure; the severity of ADHD increased after epilepsy onset, even after seizure drug-control was achieved.

The screening for genomic imbalances by array-CGH was performed in 6 of 15 patients, as the first step in a multi-tiered genetic investigation algorithm. Five patients had only benign copy number variants (CNVs). An interstitial 22q11.2 microduplication was detected in one patient (patient 3, Table I). The genomic anomaly spans 2.61 Mb [arr[GRCh37]22q11.21 (18877583x2,18894835_21505417x3,21540288x2)] and includes 76 annotated genes out of which 42 are included in Online Mendelian Inheritance In Man (OMIM). The patient, a 16-year-old boy, presented drug-resistant epilepsy, mild intellectual disability, ADHD and left occipital heterotopia.

\section{Discussion}

The focus of the present study was on the clinical and genetic characteristics of a cohort of 15 pediatric patients with heterotopia, to the best of our knowledge, the first Romanian report on this condition. All 15 patients had nodular heterotopia with only one exception, an infant with a complex brain malformation, which included band heterotopia, lissencephaly and corpus callosum agenesis.

Few pediatric cohorts with heterotopia have been reported to date $(21,32)$ with heterogeneous clinical and imagistic 
presentations as well as genetic defects. As reported in previous patients, epilepsy and intellectual disability/developmental delay were the most common clinical findings in the group included in the present study. The epileptic seizures were the main clinical reason for presentation in our department. The number of antiepileptic drugs administered varied between 1 and 5 with a mean of 2 per patient. Of the 13 patients, 6 patients with epilepsy had drug-resistant seizures and 8 of the epilepsy patients were seizure-free at last follow-up; however, more than one antiepileptic drug was needed for seizure control in 3 patients and surgical intervention in 1 patient. Intellectual disability or developmental delay, which are common features reported in heterotopia $(12,21,33)$, were present in 8 out of 15 patients, in most cases in a mild form. In addition, 5 patients presented behavioral problems, including autism and ADHD, similar with previous reports (34). Wegiel et al (33) found heterotopia in 4 of 13 children with autism, and Zając-Mnich et al (12) reported the presence of behavioral problems in $25-30 \%$ of patients with heterotopia.

Some clinical and evolution characteristics of the patients of the current study resembled more closely those of adult cohorts $(19,33)$ and to a lesser degree the largest pediatric cohort reported by Srour et al (21). Thus, no systemic malformations besides those affecting the brain were detected in the present cohort and the rate of mortality was zero at last follow-up; similar data were reported for adult patients $(19,35,36)$. In contrast, the cohort described by Srour et al (21) included $74 \%$ of cases with systemic malformations and a high rate of mortality in the neonatal period or childhood, mostly due to multiple congenital malformations. This may be explained by the small number of patients in the present cohort and by the differences in cohort set-up criteria (many newborns with a diagnosis of heterotopia established prenatally, in the published data).

One duplication of $22 \mathrm{q} 11.2$ region was detected by array-CGH in the present group, in a patient with left occipital nodular heterotopia. The $22 \mathrm{q} 11.2$ region is prone to genomic imbalances due to the presence of flanking blocks of low copy repeats, both deletions and duplications being reported. Deletion of $22 \mathrm{q} 11.2$, with a typical size of $\sim 3 \mathrm{Mb}$ or seldom of $\sim 1.5 \mathrm{Mb}$, is responsible for the $22 \mathrm{q} 11.2$ deletion syndrome, formerly known as DiGeorge or velocardiofacial syndrome. The 22q11.2 deletion syndrome has a complex and variable phenotype with multiple organ and system anomalies (37), including GMH in rare patients $(27,28,38)$. The same $22 \mathrm{q} 11.2$ region, when duplicated, can be responsible for 22 q11.2 duplication syndrome (OMIM no. 608363). The duplication size is in most patients the typical $\sim 3 \mathrm{Mb}$ observed in the 22q11.2 deletion syndrome. However, atypical duplications, ranging from 1.5 to $6 \mathrm{Mb}$ were reported. The patients with 22 q11.2 duplication syndrome have a milder phenotype, compared to those with deletions of the same region, with high variability ranging from asymptomatic to severe forms. The most commonly reported features include delayed psychomotor development with learning and speech difficulties (39). However, at present, there are no published reports of patients with 22q11.2 duplication and GMH. Given the fact that the 22 q11.2 imbalances (deletions only) are rarely associated with $\mathrm{GMH}$, and that none of the genes in this region were specifically associated with heterotopia, the role of $22 \mathrm{q} 11.2$ rearrangements in heterotopia pathogenesis is difficult to assess.

The small size of the patient cohort is a limitation of the present study. However, as GMH is a rare disorder any new phenotypic and genomic data increase the knowledge regarding the clinical and biological characteristics of these diseases. With the exception of the cohort of Srour et al (21) with 31 patients, the remaining pediatric cohorts have less than 10 patients per study.

Future perspectives of the present study envisage increasing the patient group and expanding the genetic algorithm with mutational screening.

In conclusion, the results focused on clinical and genomic investigations on a small pediatric heterotopia cohort, consisting of 15 patients. New data on the clinical features and epilepsy phenotypes were identified. Moreover, the genomic investigation in the current patient group revealed a chromosomal anomaly not reported thus far in heterotopia patients.

\section{Acknowledgements}

We would like to thank the patients and their families for participating in this study.

\section{Funding}

This work was supported partially by grants of the Romanian National Authority for Scientific Research and Innovation CCCDI-UEFISCDI, Projects COFUND-ERANET E-RARE 3-HETER-OMICS-2 nos. 87/2019 and 88/2019, within PNCDI III and by Core Programme Project PN 19.29.01.03.

\section{Availability of data and materials}

The data and materials used and/or analyzed during the current study are available from the corresponding author on reasonable request.

\section{Authors' contributions}

All authors made substantial contributions as follows: MB, SMP and AA substantially contributed to conception and design. AA, SMP, AE, MD, CI, DB, OTA, CM, AD, CS, CA, $\mathrm{DC}$ contributed to acquisition, analysis, and interpretation of data. MB, SMP and AA drafted the manuscript. All authors critically revised the manuscript for important intellectual content and approved the final version for submission.

\section{Ethics approval and consent to participate}

This study was approved by the Ethics Committee of 'Prof. Dr. Alex. Obregia' Clinical Hospital of Psychiatry, Bucharest (approval no. 32190/16.10.2019), and 'Victor Babes' National Institute of Pathology Bucharest, Romania (approval no. 68/14.09.2019). Written informed consent was obtained from all parents or legal guardians of patients.

\section{Patient consent for publication}

Not applicable. 


\section{Competing interests}

The authors declare that they have no competing interests.

\section{References}

1. Barkovich AJ, Guerrini R, Kuzniecky RI, Jackson GD and Dobyns WB: A developmental and genetic classification for malformations of cortical development: Update 2012. Brain 135 $1348-1369,2012$

2. Watrin F, Manent JB, Cardoso C and Represa A: Causes and consequences of gray matter heterotopia. CNS Neurosci Ther 21: 112-122, 2015.

3. Franzoni E, Bernardi B, Marchiani V, Crisanti AE, Marchi R and Fonda C: Band Brain heterotopia. Case report and literature review. Neuropediatrics 26: 37-40, 1995.

4. Pang T, Atefy R and Sheen V: Malformations of cortical development. Neurologist 14: 181-191, 2008.

5. Represa A: Why malformations of cortical development cause epilepsy. Front Neurosci 13: 250, 2019.

6. Tocchio S, Kline-Fath B, Kanal E, Schmithorst VJ and Panigrahy A: MRI evaluation and safety in the developing brain. Semin Perinatol 39: 73-104, 2015.

7. Gawlik-Kuklinska K, Wierzba J, Wozniak A, Iliszk M Debiec-Rychter M, Dubaniewicz-Wybieralska M and Limon J: Periventricular heterotopia in a boy with interstitial deletion of chromosome 4p. Eur J Med Genet 51: 165-171, 2008.

8. Conti V, Carabalona A, Pallesi-Pocachard E, Parrini E, Leventer R, Buhler E, McGillivray G, Michel F, Striano P, Mei D, et al: Periventricular heterotopia in $6 \mathrm{q}$ terminal deletion syndrome: Role of the C6orf70 gene. Brain 136: 3378-3394, 2013

9. Nishigaki S, Hamazaki T, Saito M, Yamamoto T, Seto T and Shintaku H: Periventricular heterotopia and white matter abnormalities in a girl with mosaic ring chromosome 6 . Mol Cytogenet 8: 54, 2015

10. Jones K, Weiss S and Minassian B: Infantile spasms with periventricular nodular heterotopia, unbalanced chromosomal translocation 3p26.2-10p15.1 and 6q22.31 duplication. Clin Case Rep 4: 675-677, 2016.

11. Cellini E, Vetro A, Conti V, Marini C, Doccini V, Clementella C, Parrini E, Giglio S, Della Monica M, Fichera M, et al: Multiple genomic copy number variants associated with periventricular nodular heterotopia indicate extreme genetic heterogeneity. Eur J Hum Genet 27: 909-918, 2019.

12. Zajac-Mnich M, Kostkiewicz A, Guz W, Dziurzyńska-Białek E, Solińska A, Stopa J and Kucharska-Miąsik I: Clinical and morphological aspects of gray matter heterotopia type developmental malformations. Pol J Radiol 79: 502-507, 2014.

13. Barkovich J and Kuzniecky RI: Gray matter heterotopia. Neurology 55: 1603-1608, 2000.

14. Bahi-Buisson N, Souville I, Fourniol FJ, Toussaint A, Moores CA, Houdusse A, Lemaitre JY, Poirier K, Khalaf-Nazzal R, Hully M, et al: New insights into genotype-phenotype correlations for the double cortin-related lissencephaly spectrum. Brain 136 223-244, 2013

15. Pilz DT, Matsumoto N, Minnerath S, Mills P, Gleeson JG Allen KM, Walsh CA, Barkovich AJ, Dobyns WB, Ledbetter DH and Ross ME: LIS1 and XLIS (DCX) mutations cause most classical lissencephaly, but different patterns of malformation. Hum Mol Genet 7: 2029-2037, 1998.

16. Cardoso C, Leventer RJ, Dowling JJ, Ward HL, Chung J, Petras KS, Roseberry JA, Weiss AM, Das S, Martin CL, et al: Clinical and molecular basis of classical lissencephaly: Mutations in the LIS1 gene (PAFAH1B1). Hum Mutat 19: 4-15, 2002.

17. Kielar M, Tuy FP, Bizzotto S, Lebrand C, de Juan Romero C, Poirier K, Oegema R, Mancini GM, Bahi-Buisson N, Olaso R, et al: Mutations in Emll lead to ectopic progenitors and neuronal heterotopia in mouse and human. Nat Neurosci 17: 923-933, 2014

18. D'Agostino MD, Bernasconi A, Das S, Bastos A, Valerio RM, Palmini A, Costa da Costa J, Scheffer IE, Berkovic S, Guerrini R, et al: Subcortical band heterotopia (SBH) in males: Clinical, imaging and genetic findings in comparison with females. Brain 125: 2507-2522, 2002.

19. Parrini E, Ramazzotti A, Dobyns WB, Mei D, Moro F, Veggiotti P, Marini C, Brilstra EH, Dalla Bernardina B, Goodwin L, et al: Periventricular heterotopia: Phenotypic heterogeneity and correlation with Filamin A mutations. Brain 129: 1892-1906, 2006
20. Clapham KR, Yu TW, Ganesh VS, Barry B, Chan Y, Mei D, Parrini E, Funalot B, Dupuis L, Nezarati MM, et al: FLNA genomic rearrangements cause periventricular nodular heterotopia. Neurology 78: 269-278, 2012.

21. Srour M, Rioux MF, Varga C, Lortie A, Major P, Robitaille Y, Decarie JC, Michaud J and Carmant L: The clinical spectrum of nodular heterotopias in children: Report of 31 patients. Epilepsia 52: 728-737, 2011.

22. Cappello S, Gray M, Badouel C, Lange S, Einsiedler M, Srour M, Chitayat D, Hamdan FF, Jenkins ZA, Morgan T, et al: Mutations in genes encoding the cadherin receptor-ligand pair DCHS1 and FAT4 disrupt cerebral cortical development. Nat Genet 45: 1300-1308, 2013

23. Heinzen E, O'Neill A, Zhu X, Allen A, Bahlo M, Chelly J, Chen MH, Dobyns W, Freytag S, Guerrini R, et al: De novo and inherited private variants in MAP1B in periventricular nodular heterotopia. PLoS Genet 14: e1007281, 2018.

24. Small K and Warren ST: Emerin deletions occurring on both Xq28 inversion backgrounds. Hum Mol Genet 7: 135-139, 1998.

25. Chardon JW, Mignot C, Aradhya S, Keren B, Afenjar A, Kaminska A, Beldjord C, Héron D and Boycott K: Deletion of filamin A in two female patients with periventricular nodular heterotopia. Am. J Med Genet A 158A: 1512-1516, 2012.

26. Tsao CY, Wenger GD and Bartholomew DW: Cri du chat syndrome and complex karyotype in a patient with infantile spasms, hypsarrhythmia, nonketotic hyperglycinemia, and heterotopia. Am J Med Genet A 134A: 198-201, 2005.

27. Kiehl TR, Chow EW, Mikulis DJ, George SR and Bassett AS: Neuropathologic features in adults with 22q11.2 deletion syndrome. Cereb Cortex 19: 153-64, 2009.

28. van Kogelenberg M, Ghedia S, McGillivray G, Bruno D, Leventer R, MacDermot K, Nelson J, Nagarajan L, Veltman JA, Brouwer AP, et al: Periventricular heterotopia in common microdeletion syndromes. Mol Syndromol 1: 35-41, 2010.

29. South S, Lee C, Lamb AN, Higgins AW and Kearney HM; Working Group for the American College of Medical Genetics and Genomics Laboratory Quality Assurance Committee: ACMG Standards and Guidelines for constitutional cytogenomic microarray analysis, including postnatal and prenatal applications: Revision 2013. Genet Med 15: 901-909, 2013.

30. Online Mendelian Inheritance in Man. https://omim.org/ Accessed September 27, 2020.

31. Firth HV, Richards SM, Bevan AP, Clayton S, Corpas M, Rajan D, Van Vooren S, Moreau Y, Pettett RM and Carter NP: DECIPHER: Database of chromosomal imbalance and phenotype in humans using Ensembl resources. Am J Hum Genet 84: 524-533, 2009 .

32. Spalice A, Taddeucci G, Perla FM, Pascali MP and Iannetti P. Periventricular nodular heterotopia: Report of a pediatric series. J Child Neurol 17: 300-304, 2002.

33. Wegiel J, Kuchna I, Nowicki K, Imaki H, Wegiel J, Marchi E, Ma SY, Chauhan A, Chauhan V, Bobrowicz TW, et al: The neuropathology of autism: Defects of neurogenesis and neuronal migration, and dysplastic changes. Acta Neuropathol 119: 755-770, 2010.

34. Dubeau F, Tampieri D, Lee N, Andermann E, Carpenter S, Leblanc R, Olivier A, Radtke R, Villemure JG and Andermann F: Periventricular and subcortical nodular heterotopia. A study of 33 patients. Brain 118: 1273-1287, 1995.

35. Battaglia G, Granata T, Farina L, D'Incerti L, Franceschetti S and Avanzini G: Periventricular nodular heterotopia: Epileptogenic findings. Epilepsia 38: 1173-1182, 1997.

36. Battaglia G, Chiapparini L, Franceschetti S, Freri E, Tassi L, Bassanini S, Villani F, Spreafico R, D'Incerti L and Granata T: Periventricular nodular heterotopia: Classification, epileptic history, and genesis of epileptic discharges. Epilepsia 47: 86-97, 2006.

37. Bassett AS, Chow EW, Husted J, Weksberg R, Caluseriu O, Webb GD and Gatzoulis MA: Clinical features of 78 adults with 22q11 deletion syndrome. Am J Med Genet A 138: 307-313, 2005.

38. Rezazadeh A, Bercovici E, Kiehl TR, Chow EW, Krings T, Bassett AS and Andrade DM: Periventricular nodular heterotopia in 22q11.2 deletion and frontal lobe migration. Ann Clin Transl Neurol 5: 1314-1322, 2018.

39. Wentzel C, Fernström M, Ohrner Y, Annerén G and Thuresson AC: Clinical variability of the 22q11.2 duplication syndrome. Eur J Med Genet 51: 501-510, 2008. 